\title{
Retrieval of subvisual cirrus cloud optical thickness from limb-scatter measurements
}

\author{
J. T. Wiensz ${ }^{1,2}$, D. A. Degenstein ${ }^{1}$, N. D. Lloyd ${ }^{1}$, and A. E. Bourassa ${ }^{1}$ \\ ${ }^{1}$ Institute of Space and Atmospheric Studies, University of Saskatchewan, Saskatoon, Canada \\ ${ }^{2}$ SRON Netherlands Institute for Space Research, Utrecht, The Netherlands
}

Correspondence to: J. T. Wiensz (truitt.wiensz@usask.ca)

Received: 13 June 2012 - Published in Atmos. Meas. Tech. Discuss.: 2 August 2012

Revised: 14 November 2012 - Accepted: 19 December 2012 - Published: 22 January 2013

\begin{abstract}
We present a technique for estimating the optical thickness of subvisual cirrus clouds detected by OSIRIS (Optical Spectrograph and Infrared Imaging System), a limbviewing satellite instrument that measures scattered radiances from the UV to the near-IR. The measurement set is composed of a ratio of limb radiance profiles at two wavelengths that indicates the presence of cloud-scattering regions. Cross-sections and phase functions from an in situ database are used to simulate scattering by cloud-particles. With appropriate configurations discussed in this paper, the SASKTRAN successive-orders of scatter radiative transfer model is able to simulate accurately the in-cloud radiances from OSIRIS. Configured in this way, the model is used with a multiplicative algebraic reconstruction technique (MART) to retrieve the cloud extinction profile for an assumed effective cloud particle size. The sensitivity of these retrievals to key auxiliary model parameters is shown, and it is shown that the retrieved extinction profile, for an assumed effective cloud particle size, models well the measured in-cloud radiances from OSIRIS. The greatest sensitivity of the retrieved optical thickness is to the effective cloud particle size. Since OSIRIS has an 11-yr record of subvisual cirrus cloud detections, the work described in this manuscript provides a very useful method for providing a long-term global record of the properties of these clouds.
\end{abstract}

\section{Introduction}

Subvisual cirrus clouds (SVC) are thought to affect the radiative balance of the uppermost tropical troposphere with a net positive radiative forcing (Wang et al., 1996). In addition, these clouds are thought to play a key role in stratospheric dehydration through "freeze drying" air to the saturation vapor pressure at the cold-point tropopause temperature as it slowly ascends through the tropical tropopause layer (TTL). However, the presence of high in-cloud relative humidities from recent in situ campaigns (Lawson et al., 2008; Jensen et al., 2008) indicate that both the activation efficiency of ice nuclei in this region and the uncertainty between water vapor measurements in this region challenge aspects of this hypothesis. In addition, the frequencies of occurrence of subvisual cirrus in the TTL from the Stratospheric Aerosol and Gas Experiment (SAGE) II (Wang et al., 1996) and Cloud-Aerosol Lidar and Infrared Pathfinder Satellite Observations (CALIPSO) (Fu et al., 2007) do not compare well (Fueglistaler et al., 2009). Further study of the occurrence and optical properties of these clouds is needed. Although these clouds occur predominantly in the TTL, they are also observed less frequently at mid-latitudes. Observations of these clouds have primarily been made since the beginning of lidar and occultation measurements, due to their extremely tenuous physical characteristics.

The first in situ samplings of SVC were measured by Heymsfield (1986), in which an extremely cold cloud $\left(-83^{\circ} \mathrm{C}\right)$ was sampled in the western Pacific warm pool, which indicated relatively small particles - with size distribution modes near 10 and $50 \mu \mathrm{m}$ maximum dimension based on measurements with a forward scattering spectrometer probe (FSSP) and a formvar replicator. More recent in situ measurements (Lawson et al., 2008), which were taken with Cloud Particle Imager (CPI) measurements, indicate larger ice crystal sizes, with maximum dimensions of up to $100 \mu \mathrm{m}$. The habit distributions reported in the more recent 
studies also display more tendency toward quasi-spherical and hexagonal plate geometry, in contrast with the hexagonal columns, plates, and bullet rosettes reported earlier.

A global climatology of SVC was reported by Wang et al. (1996) from the SAGE II solar occultation instrument. This provided a long-term global record of the distributions and optical thicknesses of subvisual cirrus that lasted until 2005. Subsequent to this, similar measurements of SVC were made with infrared limb sounders, namely by CLAES (Cryogenic Limb Array Etalon Spectrometer, Mergenthaler et al., 1999), CRISTA (Cryogenic Infrared Spectrometers and Telescopes for the Atmosphere, Spang et al., 2002), and MIPAS (Michelson Interferometer for Passive Atmospheric Sounding, Spang et al., 2012). The development of space-based lidar, particularly with the Cloud-Aerosol Lidar with Orthogonal Polarization (CALIOP) lidar on the CALIPSO satellite, have provided SVC detections since 2006. Frequencies of occurrence from CALIPSO were reported by Martins et al. (2011) with investigations into climatological relations with water vapor. In addition to these measurements and investigations, SVC have been routinely observed (Bourassa et al., 2005) by the Optical Spectrograph and InfraRed Imaging System (OSIRIS) instrument, which measures scattered sunlight in a limb-viewing geometry. This instrument was launched on the Odin satellite in early 2001 and continues to give a global occurrence distribution of SVC, in addition to distributions of key trace species such as $\mathrm{O}_{3}$ (Degenstein et al., 2009), $\mathrm{NO}_{2}$ (Bourassa et al., 2011), and stratospheric sulphate aerosols (Bourassa et al., 2007, 2012). The optical properties of the clouds observed during this period provide a valuable addition to the study of the distributions and radiative characteristics of SVC.

In this work we introduce a method for retrieving the optical properties of thin cirrus clouds from OSIRIS limbscattering measurements that is based on spectral modeling. We use a successive-orders of scatter (SOS) model with fully spherical geometry to simulate the limb radiances of cirrus clouds measured by OSIRIS, and to perform retrievals of cloud optical thickness for an assumed effective particle size. This paper is constructed as follows: Sect. 2 introduces the presence of SVC in OSIRIS measurements. Section 3 provides a description of the radiative transfer model and its configuration for modeling optically thin cirrus observations. Section 4 presents the effect of cloud parameter variations on agreement with the measurements. A retrieval technique is used to derive cloud optical thickness in Sect. 5, and the sensitivity of the retrieved results to model parameters is described in Sect. 6. Significant results and implications for future studies are described in Sect. 7.

\section{Thin cirrus observations with OSIRIS}

Thin and subvisual cirrus clouds are observed by OSIRIS as enhancements to the predominantly Rayleigh-scattering background limb radiance (Bourassa et al., 2005). OSIRIS, the Optical Spectrograph and InfraRed Imaging System (Llewellyn et al., 2004), measures molecular emissions and scattered sunlight in the atmospheric limb. OSIRIS consists of two subsystems, an optical spectrograph (OS) that measures scattered sunlight between 280 and $810 \mathrm{~nm}$ with approximately $1 \mathrm{~nm}$ resolution, and an infrared imaging (IRI) system that measures excited $\mathrm{O}_{2}$ and $\mathrm{OH}$ emissions in channels at $1.26,1.27$, and $1.53 \mu \mathrm{m}$. The optical axes of the two subsystems are coaligned and point on-track, in the direction of travel, at the atmospheric limb. The horizontally oriented OS entrance slit scans over tangent heights between 10 and $60 \mathrm{~km}$ to obtain profiles of scattered solar radiance spectra.

In the upper troposphere and lower stratosphere (UTLS), OSIRIS spectra frequently show enhancements to the limbscattered signal at long wavelengths that correspond well to known geographical distributions of subvisual cirrus. The spectral radiances from a scan that suggests the presence of a thin cirrus cloud is shown in Fig. 1a. The $750 \mathrm{~nm}$ radiance profile shown in the middle panel displays the radiance normalized with respect to the radiance at $37 \mathrm{~km}$. The potential temperature tropopause, $\Theta_{380 \mathrm{~K}}$, for this location as determined from NCEP (National Centers for Environmental Prediction) 6-h reanalysis data (Kistler et al., 2001), is indicated by a dashed line in the radiance profile. For observations in the tropics, with which we are concerned in this work, this altitude serves as a good definition for the local tropopause (Holton et al., 1995). The data missing between 475 and $530 \mathrm{~nm}$ result from the spectral order sorter in the OS diffraction grating. For this scan, the radiance profile shows a significant enhancement at $15.5 \mathrm{~km}$ tangent altitude above the background Rayleigh-scattered radiance. The measured spectrum at this tangent altitude is indicated by the red line in the left-hand panel. A concurrent full-disk image from the GOES-11 (Geostationary Operational Environmental Satellite) $10.7 \mu \mathrm{m}$ channel is shown in Fig. $1 b$. The cloud observed by OSIRIS is located over the western Pacific warm pool, at $\left(178^{\circ} \mathrm{E}, 14^{\circ} \mathrm{S}\right)$, with cloud-top altitude at approximately $16 \mathrm{~km}$. The scattering volume and approximate region of influence are indicated by the solid line and dashed ellipse, respectively. The region of influence for single-scattering shows no significant presence of cirrus. During the measurement period, Odin is moving southward through the region less shortly after local sunrise. The solar zenith angle is $\theta_{0}=72.2^{\circ}$, and the solar scattering angle is $\Theta_{0}=88.8^{\circ}$. Many such observations that strongly suggest the presence of thin cirrus clouds are routinely made with OSIRIS.

The measured spectrum observed inside a cloud region, shown in Fig. 1, characteristically displays "flattening" with respect to a clear-sky spectrum, as illustrated in Fig. 2. In this figure the in-cloud radiance is shown relative to the average of several cloud-free exposures that have been interpolated to the tangent altitude of the in-cloud exposure. 


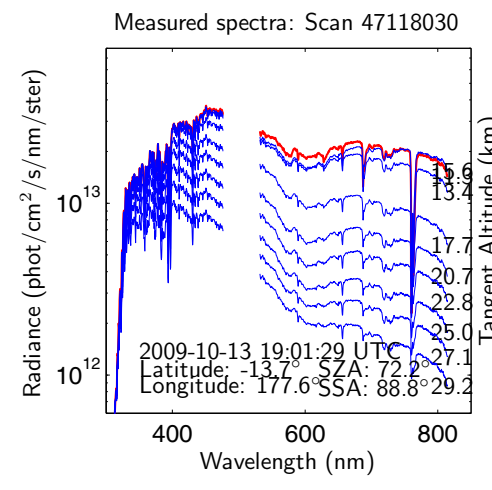

(a) OSIRIS

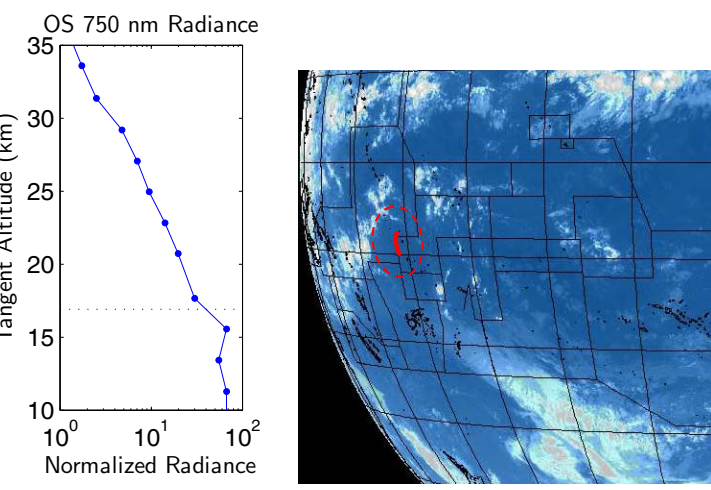

(b) GOES-11

Fig. 1. (a) OSIRIS limb spectra and $750 \mathrm{~nm}$ radiance profile from 13 October 2009, 19:01 UTC; (b) concurrent GOES-11 $10.7 \mu \mathrm{m}$ full-disk image.

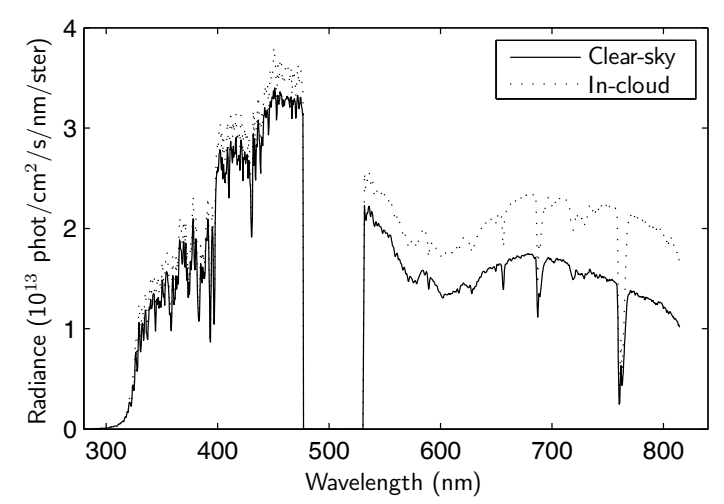

Fig. 2. OSIRIS in-cloud radiance shown with respect to clear-sky radiances observed at the same altitude.

\section{Thin cirrus modeling with SASKTRAN}

\subsection{Radiative transfer in thin cirrus}

In this work, we focus on simulating the observed scattering of solar irradiance by ice crystals within cirrus clouds. For the light-scattering properties of typical cirrus cloud ice crystals we use properties from the database of Baum et al. (2005), which are derived from in situ measurements of a large number of particle size distributions. In this database the relative amounts of various particle shapes (quasi-spheroids, hexagonal plates and columns, rosettes) are fixed over four effective size ranges. For the range of effective sizes with which we are concerned - between $D_{\mathrm{e}}=10 \mu \mathrm{m}$ and $70 \mu \mathrm{m}$ - these fixed compositions are consistent with compositions observed in current in situ studies. Ice crystals are assumed to be randomly oriented. We consider observations within optically thin cirrus clouds - typically with cloud optical thickness $\tau_{\mathrm{c}} \leq 0.1-$ and as such, it is possible to model the in-cloud scattering processes with a ray-tracing, successive-orders of scattering model.
Although the limb-viewing geometry of OSIRIS is wellsuited to the detection of thin cirrus clouds, limb-scattering measurements of clouds present several challenges for radiative transfer modeling. Assuming a horizontally homogeneous, thin cloud layer between 15 and $16 \mathrm{~km}$ through which an OS exposure passes and which is tangent at $15 \mathrm{~km}$ altitude, the instrument line of sight (LOS) passes through approximately $\Delta s=225 \mathrm{~km}$ of the cloud. If this cloud has $\tau=0.3$, and is assumed for the moment to be vertically homogeneous, then the optical depth along the LOS is near 70. Even for this very thin cloud, since a large number of scattering events occur along this segment of the instrument LOS, the model used for retrievals must ensure that the path discretization ably resolves these scattering events.

The vertical distribution of measurements also affects the potential accuracy of cloud property measurements. The vertical field of view of the OS is approximately $1 \mathrm{~km}$ at the tangent point. Successive exposures are typically separated by $1.5-2 \mathrm{~km}$ in tangent altitude. Since typical vertical thicknesses of SVC are $<1 \mathrm{~km}$ (Lynch et al., 2002), typically only one to three OS exposures are directly affected by an SVC layer. Since a small number of observations through the cloud are available, we assume it is sufficient to describe a cirrus cloud in terms of a single effective particle size and a number density that is a function of height alone for modeling observations made by OSIRIS.

\subsection{SASKTRAN geometry and ray-tracing algorithm}

In this work we use the SASKTRAN radiative transfer model (Bourassa et al., 2008), which employs a successive-orders of scatter solution within a fully spherical geometry. The unpolarized radiance $I$ modeled by SASKTRAN for any ray, defined with respect to an observer located at $s=0$, looking in a direction $\hat{\Omega}$, along a ray that terminates at $s_{1}$, is computed as 
$I(0, \hat{\Omega})=\tilde{I}\left(s_{1}, \hat{\Omega}\right) e^{-\tau\left(s_{1}, 0\right)}+\int_{s_{1}}^{0} J(s, \hat{\Omega}) e^{-\tau(s, 0)} k(s) \mathrm{d} s$.

Contributions from thermal emissions are negligible in the signals of interest, and the path integral in the second term evaluates the multiple scattering source term along the observer line of sight through evaluating the source function:

$J(s, \hat{\Omega})=\tilde{\Omega}(s) \int_{4 \pi} \bar{P}\left(s, \hat{\Omega}, \hat{\Omega}^{\prime}\right) I\left(s, \hat{\Omega}^{\prime}\right) \mathrm{d} \Omega^{\prime}$,

for each scattering order at a set of points a distance $s$ from the observer. In this expression $\tilde{\Omega}$ and $P$ denote the singlescattering albedo and scattering phase function, respectively.

The fundamental unit of the model is a ray that originates at a location $\boldsymbol{r}$ and which extends in the direction $\hat{\Omega}$ with path coordinate $s$. The nomenclature used in discussing the model atmosphere is that concentric spherical "shells" define homogeneous 'cells' that lie between them. Ray tracing is performed by finding all points of intersection with the set of spherical shells as it proceeds outward from the point $\boldsymbol{r}$ in direction $\hat{\Omega}$. Straight-line propagation is assumed in this implementation, so the path lengths through cells is the difference between successive shell intersection points. Since in limbviewing geometry the diffuse field varies slowly with solar zenith angle (Herman et al., 1994; McLinden et al., 2002), SASKTRAN uses a spherical coordinate system with the central axis oriented towards the sun. In these coordinates the radiation field is azimuthally symmetric and diffuse radiation field is solved at a discrete set of solar zenith angles, called "diffuse profiles"; each of which contains "diffuse points" distributed in altitude at which scattering events are resolved. The diffuse field is solved recursively by performing scattering and attenuation along traced rays through the 2-D diffuse point grid. The placement of the diffuse points in altitude is chosen independently of spherical ray-tracing shells.

\subsection{Scattering integral evaluation}

The scattering integral (Eq. 2) is evaluated at each diffuse point by discretizing the integral into a set of directions $\hat{\Omega}_{j}^{\prime}$ on a zenith-azimuth grid. At each diffuse point, this grid consists of 28 zenith angles - with respect to the local zenith angle - and 24 azimuth angles, defined relative to the solar direction. The zenith angles are placed such that they correspond closely to the variation in the incoming radiance field. Radiances are scattered into a set of "outbound" directions $\hat{\Omega}_{k}$, specified at 324 evenly-spaced outbound directions using a minimum-energy distribution (Sloan and Womersley, 2004). The numerical computation of the scattering integral, Eq. (2), can result in large errors for particles that are very large compared with the wavelength of light, as is the case for OSIRIS measurements of SVC scenes. To reduce these errors, SASKTRAN employs a novel photon conservation technique (Wiensz et al., 2012) together with the transport approximation (McKellar and Box, 1981) configuration. These techniques, together, improve the accuracy of scattering integral evaluations when particles with large forward-scattering diffraction peaks are encountered as in cirrus-cloud measurements in a limb-viewing geometry.

\subsection{Source function quadrature}

The path integral in Eq. (1) is performed by taking the sum of individual integrals along each of the line of sight's path segments, $\Delta s$, through the homogeneous layers of the model atmosphere. The source functions, $J(s)$, along the path are evaluated at that path segment's solar illumination conditions. Each individual path integral is evaluated using Gaussian quadrature. Since path segments through spherical shells near the tangent point become quite long, each such path integral is subdivided into sub-integrals of maximum length $5 \mathrm{~km}$ over which Gaussian quadrature is done.

\subsection{Ray-tracing shell specification}

For satellite instruments with limb-viewing geometry, the observation LOS passes through a long segment of the atmosphere, up to thousands of kilometers at low tangent altitudes. When such a ray is traced through equally-spaced spherical shells, the length of the path segments, $\Delta s$, between the nominal $1 \mathrm{~km}$ spherical shells increases significantly at the lowermost altitudes, exceeding $200 \mathrm{~km}$ at SVC altitudes. When these long path lengths coincide with typical in-cloud extinction values, the segment optical depth, $\Delta \tau_{\mathrm{s}}-$ the optical depth along a path segment through a homogeneous layer becomes quite large. These high optical depths are illustrated in Fig. 3a, in which the segment optical depths and mid-cell altitude are shown as a function of distance along the observer LOS.

To avoid these extremely high segment optical depths, we configure the ray-tracing shell spacings to the extinction of the dominant scattering particles at $750 \mathrm{~nm}$ such that the segment optical depths, $\Delta \tau_{\mathrm{s}}$, do not exceed an empirically determined threshold of $\Delta \tau_{\mathrm{s}}=0.3$ due to scattering. The optical depths per cell that result from this configuration are shown in Fig. 3b. The minimum height separation of raytracing shells, $\Delta h_{\mathrm{rt}}$, is $10 \mathrm{~m}$ at the altitude of the maximum number density and is scaled to maintain a constant cell optical depth, $\Delta \tau_{z}=k_{\mathrm{sca}}(h) \Delta h_{\mathrm{rt}}$, along the vertical direction inside the cloud region. The small "sawtooth" structure on the $\Delta \tau_{\mathrm{s}}$ curve, at the border of the cloud region (near 2600 and $2900 \mathrm{~km}$ along the LOS), occurs from the internal matching of the in-cloud shell spacing to the external shell spacing and does not affect the solution accuracy. 


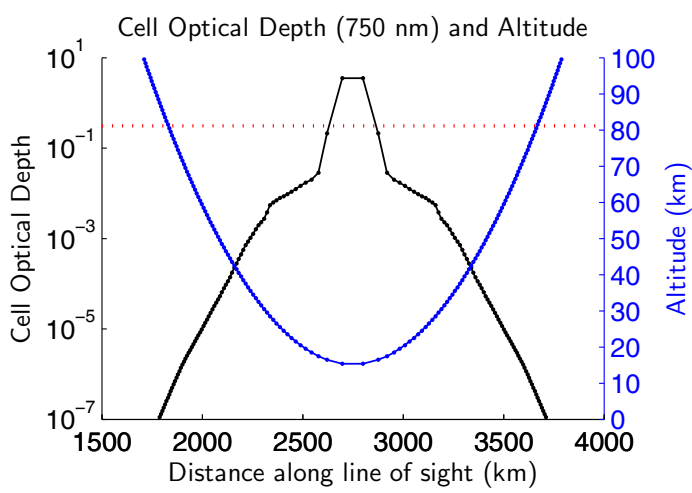

(a) $\Delta \tau_{s}$ for $1 \mathrm{~km}$ cells

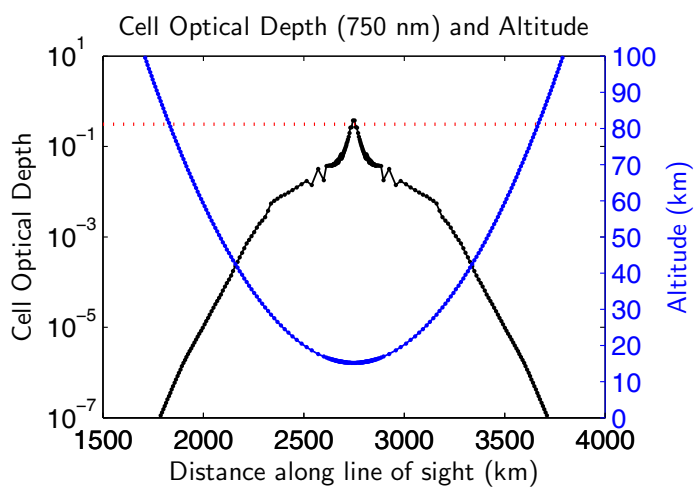

(b) $\Delta \tau_{s}$, with tapered shell spacing

Fig. 3. Cell optical depths, $\Delta \tau_{\mathrm{S}}$, shown as a function of distance $s$ along observer line of sight.

\subsection{Optical properties specification}

We assume constant optical properties within spherical cells. Scattering and absorption quantities along the observer LOS are linearly interpolated in height for evaluating the multiple scattering source term and for attenuating radiances. Simulated cloud layers in this work assume the optical properties from a single effective particle size, $D_{\mathrm{e}}$, throughout the vertical extent of the cloud using the properties of the Baum et al. (2005) database, which use a unimodal gamma distribution (Heymsfield et al., 2002). It should be noted that recent studies (Tian et al., 2010) have shown that the particle size distributions in cirrus are well-described by a lognormal distribution, however this difference has minor implications for OSIRIS SVC measurements. The spatial distribution of cloud particle number density is characterized in this work by a Gaussian height profile, $n(h)$, which is scaled to produce a prescribed cloud optical thickness, $\tau_{\mathrm{c}}$. The cloud top altitude, $h_{\mathrm{ct}}$, is assigned to the upper half-maximum point, and the cloud thickness is defined to be the full width at halfmaximum of the distribution.

For the forward model study, in Sect. 4, a modeled cloud is then characterized by the parameters $h_{\mathrm{ct}}, \Delta h_{\mathrm{c}}, D_{\mathrm{e}}$, and $\tau_{\mathrm{c}}$. When this model is applied to retrievals of cloud extinction,

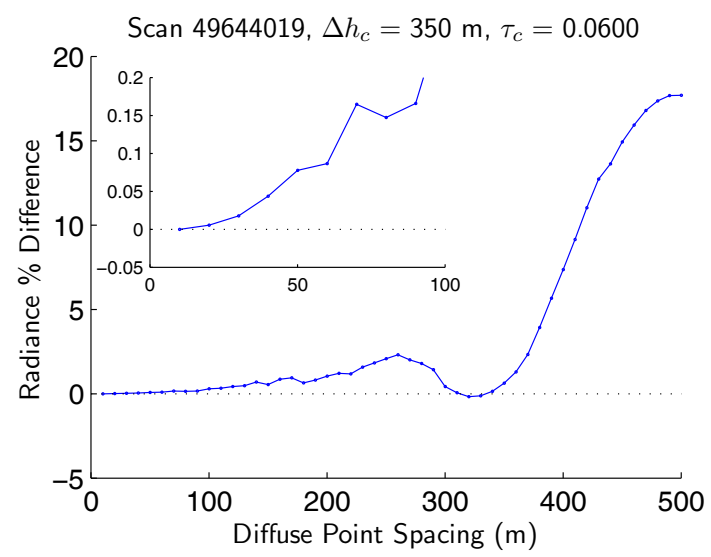

Fig. 4. Normalized modeled $750 \mathrm{~nm}$ limb radiance at $15.8 \mathrm{~km}$ tangent altitude as a function of diffuse point altitude spacing.

in Sect. 5, the cloud top altitude and cloud thickness are implicitly found through the cloud particle number density profile.

\subsection{Diffuse point configuration}

To compute the observed radiance $I(s, \hat{\Omega})$ in Eq. (1), SASKTRAN evaluates the source functions $J(s, \hat{\Omega})$ at a set of discrete points distributed in altitude and in solar zenith angle (SZA). To investigate the tradeoff between numerical accuracy and computational effort, we monitor the percent change of the simulated in-cloud radiance with respect to high-resolution base cases.

For the altitude discretization, we choose as a base case diffuse points that are separated by $10 \mathrm{~m}$ in height within the cloud region. Figure 4 shows the fractional change in the $750 \mathrm{~nm}$ in-cloud radiance as the diffuse point spacing is increased. A cirrus cloud layer between 16.15 and $16.5 \mathrm{~km}$, with $D_{\mathrm{e}}=50 \mu \mathrm{m}$ and $\tau_{\mathrm{c}}=0.06$, was used for these computations. The ray-tracing shell locations were held fixed in the extinction-dependent configuration just described. It is clear that the modeled radiance converges to a well-defined value for diffuse point spacings below $50 \mathrm{~m}$. To capture the change in radiance above and below the cloud layer, several bracketing diffuse points are placed above and below any region that contains cloud particles.

The discretization in SZA is studied similarly by varying the spacing of diffuse profiles in solar zenith angle, $\Delta \theta_{0}$. Since this effect is most evident when the SZA is large, we model in-cloud radiances for two OSIRIS scans in which the mean SZA is quite large and for which the SZA varies over the line of sight by more than $5^{\circ}$. A cloud is placed in this study between altitudes of 16.15 and $16.5 \mathrm{~km}$ with $\tau_{\mathrm{c}}=0.06$ and $D_{\mathrm{e}}=50 \mu \mathrm{m}$. For the base cases, we compute the limb radiance with diffuse profiles separated by $\Delta \theta_{0}=0.5^{\circ}$, where each profile contains diffuse points separated by $40 \mathrm{~m}$ in the cloud region. The SZAs at which the diffuse profiles 

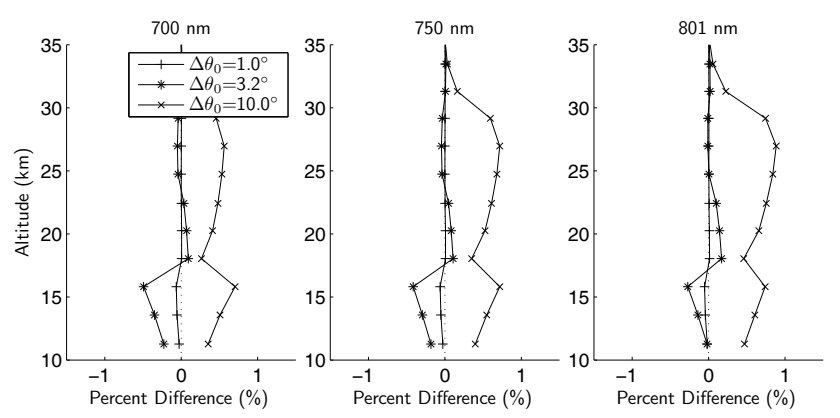

(a) OSIRIS scan 49644019: $\overline{\theta_{0}}=80.5^{\circ}$
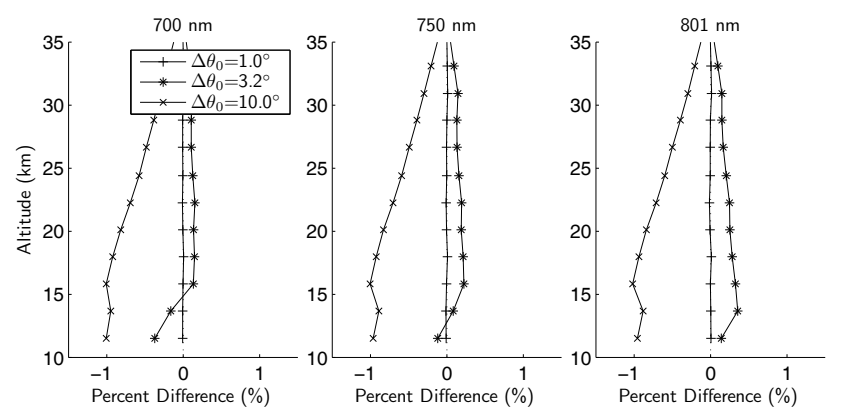

(b) OSIRIS scan 53441016: $\overline{\theta_{0}}=86.2^{\circ}$

Fig. 5. Percent difference of modeled radiance for increasing coarseness of diffuse profile spacing.

are located for the two scans in this study are listed in Table 1 . To study the effect of this change, we vary the diffuse profile spacing over one order of magnitude, from approximately one degree to ten degrees, for which only one diffuse profile is used.

The percent difference in modeled radiance is shown as a function of height, in Fig. 5, for a varying number of diffuse profile spacings for two extreme solar zenith angle cases. The percent difference in radiance from the base case are shown for diffuse profile spacings of approximately $\Delta \theta=1,3.16$, and $10^{\circ}$. For the radiances from scan 49644019 in Fig. 5a, in which the mean solar zenith angle is $80.5^{\circ}$, the base case was computed with nine diffuse profiles, and it is clear that a single diffuse profile is sufficient to compute the radiance to a precision of better than $1 \%$. For scan 53441016 in Fig. 5b, in which mean solar zenith angle is $\theta_{0}=86.2^{\circ}$, the percent difference from the benchmark case remains below $1.6 \%$ for all altitudes above $10 \mathrm{~km}$.

From these results, we find that one diffuse profile, with points spaced by $40 \mathrm{~m}$ in the cloud region, provides sufficient accuracy in modeled radiance since all clouds studied in this work have illumination conditions where the sun is, on average, higher in the sky than $\theta_{0}=81^{\circ}$ at the measurement point.
Table 1. Diffuse profile locations for studying the effect of diffuse profile spacing.

\begin{tabular}{lrrl}
\hline & \multicolumn{3}{l}{ Diffuse profile solar zenith angles } \\
\hline \multirow{2}{*}{ Scan } & $\overline{\theta_{0}}$ & $\Delta \theta_{0}$ & Profile locations, $\theta_{0}\left(^{\circ}\right)$ \\
\hline \multirow{3}{*}{49644019} & $80.5^{\circ}$ & $1^{\circ}$ & $77.3,78.4,79.5,80.6,81.7$ \\
& & $10^{\circ}$ & 80.5 \\
\hline & & $1^{\circ}$ & $82.0,83.2,84.3,85.4,86.6,87.7$ \\
53441016 & $86.2^{\circ}$ & $3.5^{\circ}$ & $82.0,87.7$ \\
& & $10^{\circ}$ & 86.2 \\
\hline
\end{tabular}

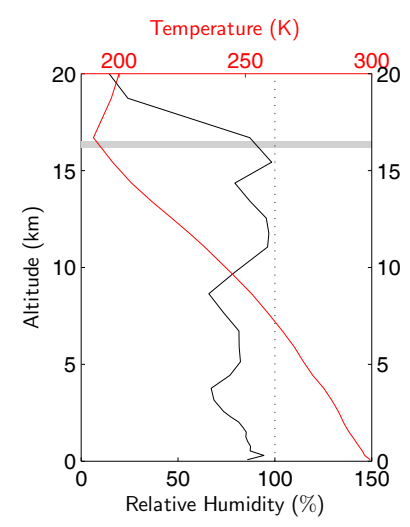

(a) Relative humidity profile (\%)

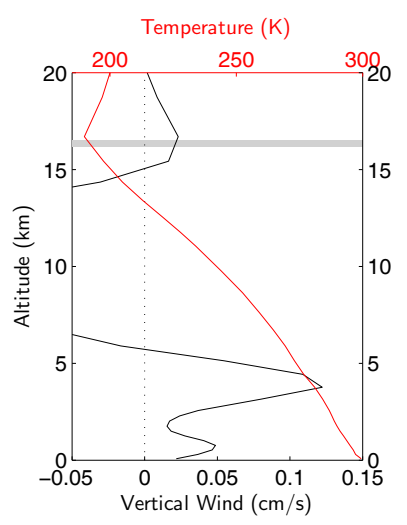

(b) Vertical wind profile $(\mathrm{cm} / \mathrm{s})$
Fig. 6. ECMWF temperature, relative humidity, and vertical wind profiles for OSIRIS scan 49644019.

\section{Simulation of OSIRIS measurements}

To demonstrate the ability of the SASKTRAN model to simulate accurately the OSIRIS limb radiance in the presence of thin cirrus clouds, we show modeled limb radiances for an OSIRIS scan as a function of the cloud parameters $D_{\mathrm{e}}$ and $\tau_{\mathrm{c}}$ and for varying surface albedo. Comparisons of the modeled and measured in-cloud spectral radiance are shown for an exposure that was taken directly through a thin cirrus cloud.

The OSIRIS measurement for this study, scan 49644019, which has a mean tangent point ground location $\left(6.5^{\circ} \mathrm{S}\right.$, $183.8^{\circ} \mathrm{E}$ ), is located over the western Pacific warm pool region. The height profiles of relative humidity, temperature, and vertical wind from the ECMWF (European Centre for Medium-Range Weather Forecasts) are shown in Fig. 6 for this scan's location. A cloud-top altitude of $16.5 \mathrm{~km}$, as determined from the relative increase in $750 \mathrm{~nm}$ limb radiance relative to the increase in molecular number density, is shown with a reference $350 \mathrm{~m}$ cloud thickness as the shaded region. At this altitude, just below the cold point tropopause, the relative humidity is near $100 \%$ and the vertical wind is slightly upwards, which supply favorable conditions for maintenance of SVC. 

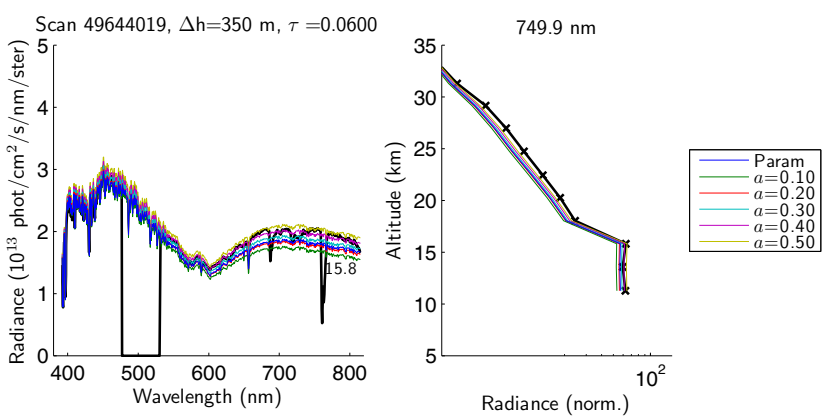

Fig. 7. Effect of varying surface albedo on simulated OSIRIS radiances. The measured data are indicated by the heavy black line. The measurement shown in the left-hand panel corresponds to $15.8 \mathrm{~km}$ tangent altitude. In the right-hand panel, the radiance profile has been normalized to the radiance at $37.5 \mathrm{~km}$ reference altitude.
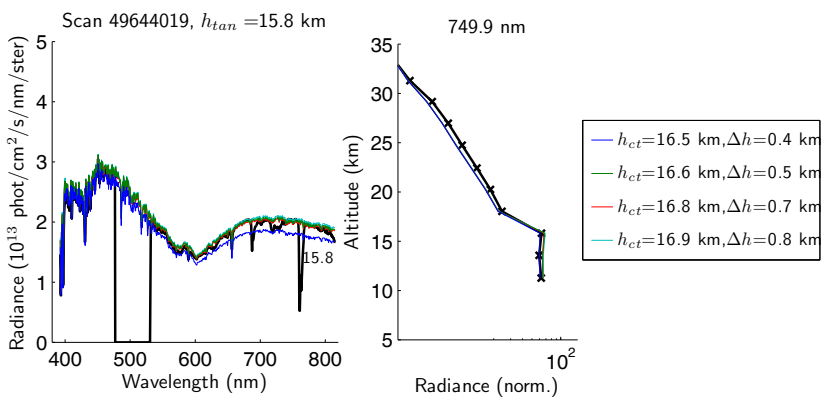

Fig. 8. Modeled in-cloud spectra and radiance profile: varying vertical thickness and cloud top height.

\subsection{Albedo configuration}

Accurate values of surface albedo are essential for estimating cloud properties from OSIRIS limb scans due to the strong sensitivity of limb-scattered radiance to the surface albedo. The surface of the earth is assumed to be a Lambertian surface in this work. The variation of modeled limb radiances with surface albedo is shown in Fig. 7. Here, the measured and modeled spectra at $15.8 \mathrm{~km}$ tangent altitude are shown. A $350 \mathrm{~m}$ thick cloud layer with effective particle size $50 \mu \mathrm{m}$ and optical thickness 0.06 was used. It is clear that the modeled radiance across the spectrum varies approximately linearly with surface albedo. Although a surface albedo near 0.4 provides a good spectral fit in our primary area of interest - between 550 and $800 \mathrm{~nm}$ - this also overestimates the measured signal at wavelengths below $550 \mathrm{~nm}$. Parameterized wavelength-dependent surface albedos for land cover (Feister and Grewe, 1995) and ocean surface (Jin et al., 2004) are used as a priori estimates for in-cloud radiance computations. The modeled radiance using a parameterized surface albedo - in this case calculated for ocean surface albedo with typical wind speed, chlorophyll concentration, and aerosol optical depth - is also shown in Fig. 7.
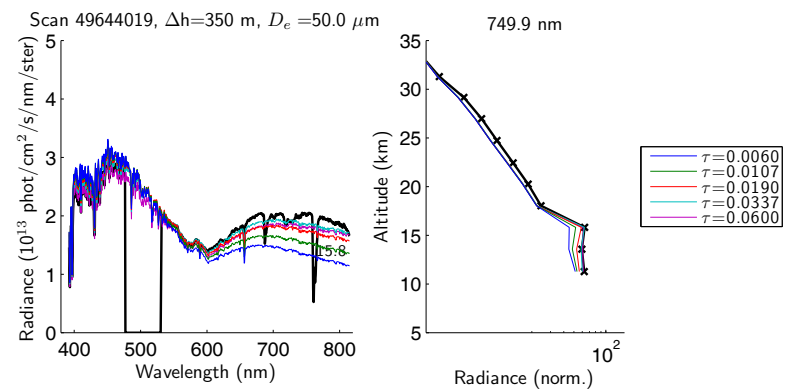

(a) In-cloud spectral radiance and $750 \mathrm{~nm}$ radiance profile

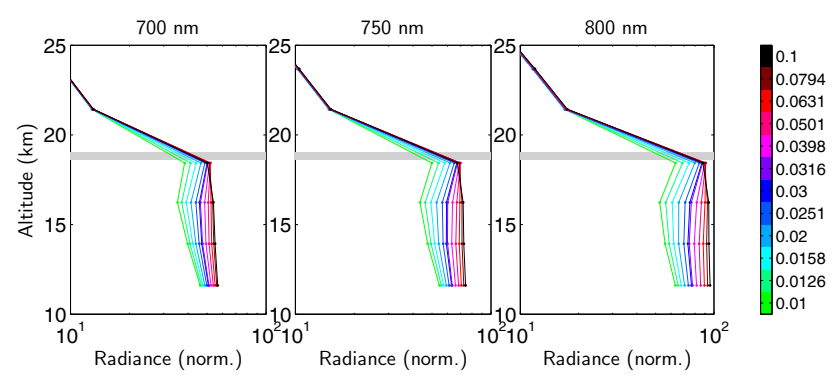

(b) Simulated limb radiance profiles

Fig. 9. Effect of varying cloud optical thickness on simulated OSIRIS radiances. The measured data in (a) are indicated by the heavy black line. In (b) the colour scale shows cloud optical thickness, $\tau_{\mathrm{c}}$.

\subsection{Cloud top and vertical thickness}

The effect of cloud-top altitude and vertical thickness, as defined in Sect. 3.6, is not readily apparent from the in-cloud radiance nor from the radiance profile due to the vertical resolution of OSIRIS tangent altitude exposures. This is shown in Fig. 8, where for a line of sight tangent at $15.6 \mathrm{~km}$, the cloud thickness is increased successively by $200 \mathrm{~m}$ above a fixed cloud bottom altitude of $15.6 \mathrm{~km}$. For this plot, the effective particle size is $50 \mu \mathrm{m}$ and the cloud optical thickness is fixed at 0.06 . The primary effect of a vertical thickening of the cloud layer is an increased radiance at longer wavelengths across the spectrum.

\subsection{Cloud optical thickness}

The changing in-cloud radiance and radiance profile for varying optical thickness are shown in Fig. 9a when a cloud layer between 16.15 and $16.5 \mathrm{~km}$ with $D_{\mathrm{e}}=50 \mu \mathrm{m}$ is used. Cloud optical thicknesses are indicated in the legend. In this figure, the limb radiance is seen to increase quite uniformly for a uniform logarithmic increase in cloud optical thickness. As well, the modeled spectrum at $\tau_{\mathrm{c}}=0.05$ is seen to match the measured spectrum very well between 550 and $800 \mathrm{~nm}$. The notable decrease in measured radiance above $795 \mathrm{~nm}$ is likely due to the uncertainty in the preflight radiance calibration of polarization effects in the grating - the Woods 

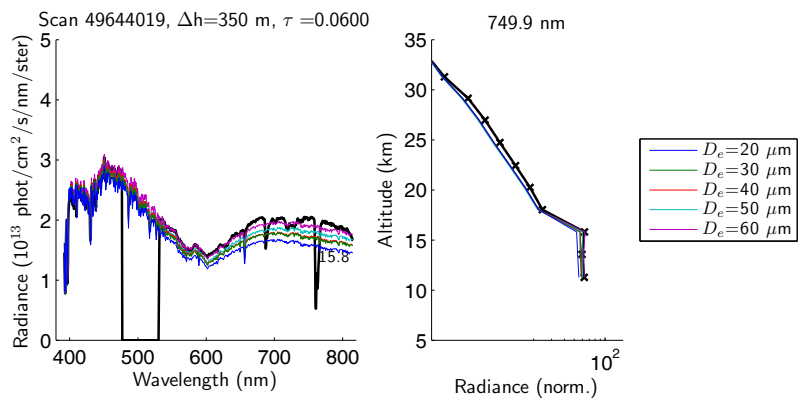

(a) In-cloud spectral radiance and $750 \mathrm{~nm}$ radiance profile

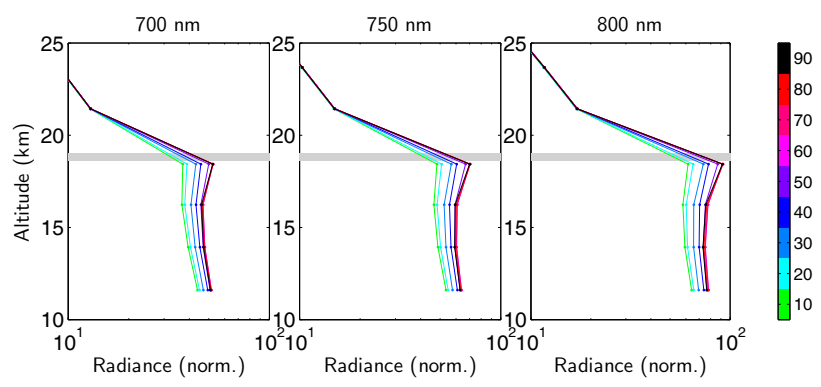

(b) Simulated limb radiance profiles

Fig. 10. Effect of varying effective cloud particle size on simulated OSIRIS radiances. The measured data in (a) are indicated by the heavy black line. In (b) the colour scale shows effective particle size, $D_{\mathrm{e}}$.

anomalies - which affect the measurement uncertainty due to the absolute calibration of the spectrograph (N. Lloyd, private communication, 2011).

It is also illustrative to view the change in the radiance profile due to an increase in cloud optical thickness for fixed cloud geometric size. The limb radiance profile for a simulated OSIRIS scan is shown in Fig. 9b for logarithmically increasing cloud optical thickness that spans the SVC threshold, $\tau_{\mathrm{c}}=0.03$. In Fig. $9 \mathrm{~b}$ it is seen that as the cloud becomes more optically thick - in this figure for values of $\tau_{\mathrm{c}} \geq 0.06-$ the radiances for lines of sight below the first sub-cloud tangent altitude become uniformly bright, and the cloud top acts as a scattering surface of increasing reflectivity.

\subsection{Cloud effective particle size}

The more strongly-scattering behaviour of larger particles is seen clearly when the effective size of simulated clouds is varied, as shown in Fig. 10a. In this figure, the in-cloud scattered radiance is seen to increase monotonically with effective size. The radiance profiles for changing effective particle size at selected wavelengths are shown in Fig. 10b. It is characteristic of scattering by larger particles that they scatter a given wavelength more strongly. As such, in limb-viewing geometry the radiance profile becomes more sharply peaked as the effective particle size increases, as seen in Fig. 10b. For

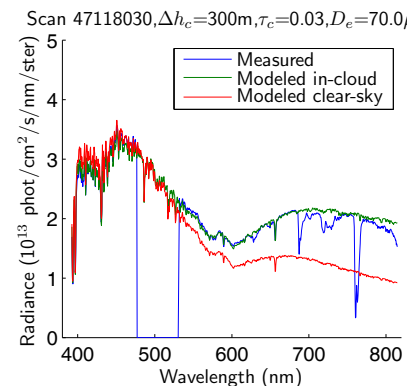

(a) Scan 47118030: radiances

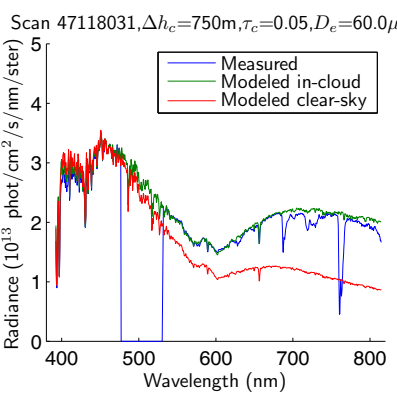

(c) Scan 47118031: radiances

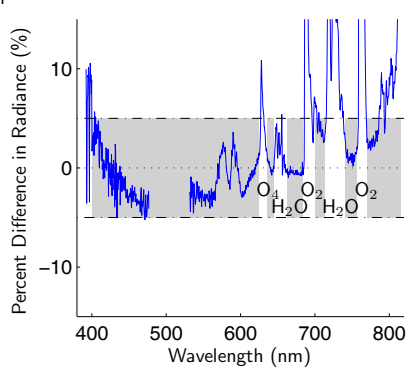

(b) Scan 47118030: differences

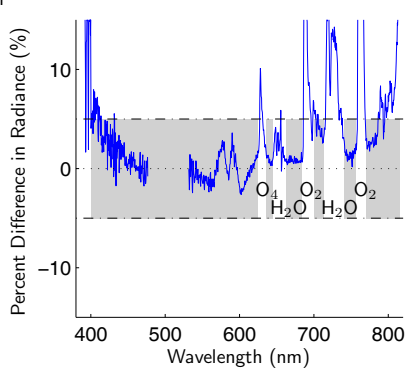

(d) Scan 47118031: differences
Fig. 11. Modeled and measured in-cloud radiances for two OSIRIS scans. Clear-sky radiances were computed with the operational OSIRIS stratospheric aerosol extinctions. Percent differences in radiance are shown with respect to the measurements.

each effective particle size, the optical thickness can be adjusted to fit the in-cloud radiance over a given spectral range.

The selection of optical properties shown in this section can be applied to OSIRIS measurements made in the presence of a more optically thick cloud layer. To illustrate, we show the modeled radiances for two successive scans: the scan shown in Fig. 1, as well as the scan immediately following it. The modeled radiances are shown together with their percent difference from the measured in-cloud spectra in Fig. 11, together with the modeled radiances when cloud properties are neglected.

For the percent differences, the modeled radiances are shown relative to the measurements. It is seen that in the highlighted regions - outside of the indicated absorption bands and at wavelengths $\lambda>400 \mathrm{~nm}$ for which the cloud properties database is defined - the modeled spectra agree with the measurements to better than $5 \%$ across the spectrum. The only exception is due to the sharp decrease in the measured signal above $790 \mathrm{~nm}$, which as mentioned previously is likely due to uncertainty in the preflight Woods anomaly calibration. The in-cloud spectral radiances of scan 47118031 indicate a more optically thick cloud layer. For these computations, the absorption features visible in the measured spectrum have not been included in the modeled calculations since this is not required for the retrieval 
technique described in this manuscript, although these can be added as necessary. An optical thickness of 0.05 matches the in-cloud spectrum very well for an effective particle size of $60 \mu \mathrm{m}$.

The clear-sky simulations in Fig. 11 were performed with the OSIRIS retrieved aerosol extinction profile, which in its current operational mode uses scattering and absorption properties of stratospheric sulphate aerosols from the Lorenz-Mie theory to match the $750 \mathrm{~nm}$ measured radiance profile. Although that method performs very well to reproduce the aerosol-dependent signal in the stratosphere (Bourassa et al., 2007), these figures highlight its inability to reproduce the measured in-cloud spectrum. This in-cloud modeling capability is now used in a retrieval technique to retrieve cloud optical thickness for an assumed effective particle size.

\section{Cloud property retrieval from OSIRIS}

We apply a multiplicative algebraic reconstruction technique (MART) relaxation algorithm (Degenstein et al., 2009) to cloud property retrievals from OSIRIS measurements where the measurement vector, $\boldsymbol{y}$, is constructed from spectral radiances at tangent altitudes surrounding the cloud region. The state to be retrieved, $\boldsymbol{x}$, is characteristically the cloud particle number density profile for an assumed particle size distribution. In applying the MART technique each element of the cloud number density at the $n$-th iteration, $x_{i}^{(n)}$, is allowed to be affected by the measurement $y_{j}$ by scaling $x_{i}^{(n)}$ by the ratio of the measurement, $y_{j}$, to its current modeled value, $F_{j}$, as

$x_{i}^{(n+1)}=x_{i}^{(n)} \sum_{j} \frac{y_{j}}{F_{j}\left(\boldsymbol{x}^{(n)}, \tilde{b}\right)} W_{i j}$.

In this expression the dependence of the modeled measurement vector at tangent altitude $j, F_{j}$, is explicitly noted by the auxiliary model parameters, $\tilde{b}$. In this formulation the empirically determined weighting factors, $W_{i j}$, relate the effect of measurement value $y_{j}$ on state value $x_{i}$. Since in the cloud property retrieval we expect a very direct relationship between the number density at altitudes near tangent point and the measured radiance, we use $W_{i j}=\delta_{i j}$, the Kronecker delta function. This is equivalent to the Chahine relaxation method (Chahine, 1972). Convergence toward a solution is considered satisfied when the fractional change in the state between iterations falls below $3 \%$ at all altitudes, which falls within the maximum measurement uncertainty of $10 \%$ at $750 \mathrm{~nm}$ (N. Lloyd, private communication, 2011). Typically fifteen iterations are sufficient for convergence. If convergence is not achieved, the scan is discarded for SVC retrievals.

\subsection{Measurement vector definition}

The measurement vector, $\boldsymbol{y}$, is constructed for each tangent altitude by first taking the logarithmic ratio of a longwavelength radiance and a short-wavelength radiance, then subtracting the same logarithmic ratio of the "background" that is, cloud- and aerosol-free - modeled radiances:

$r_{j}=\log \left(\frac{I\left(h_{j}, \lambda_{1}\right)}{I\left(h_{j}, \lambda_{\mathrm{s}}\right)}\right)-\log \left(\frac{I_{\mathrm{bg}}\left(h_{j}, \lambda_{1}\right)}{I_{\mathrm{bg}}\left(h_{j}, \lambda_{\mathrm{s}}\right)}\right)$.

In this construction, the wavelength ratio provides sensitivity to cloud particle scattering, and the background radiance offset enhances the effect of particulate scattering. The short wavelength is chosen to be $470 \mathrm{~nm}$, which is the longest wavelength on the short-wavelength side of the optical spectrograph order sorter, and is also outside any significant ozone absorption bands. The long wavelength is chosen to be $750 \mathrm{~nm}$ in order to maximize the wavelength separation while at the same time avoiding the $\mathrm{O}_{2} \mathrm{~A}$-band absorption feature near $762 \mathrm{~nm}$, the diffraction grating Woods anomalies above $780 \mathrm{~nm}$, and the $\mathrm{O}_{3}$ Chappuis absorption band. Commonly, the limb radiance profile at a given wavelength is normalized to a higher-altitude reference, which provides a measure of insensitivity to the instrument absolute calibration and also to the surface albedo. We employ a modification of this technique (Bourassa et al., 2011, 2012), in which we normalize the quantity $r_{j}$ in Eq. (4) by subtracting the average value of $r_{j}$ over a finite reference altitude range:

$y_{j}=r_{j}-\left\langle r_{\text {ref }}\right\rangle$,

where the subtraction of the mean value over a reference altitude range - between 35 and $40 \mathrm{~km}$ - better characterizes and removes the background signal. The minimum reference altitude used in the measurement vector definition, Eq. (5), is $37 \mathrm{~km}$. This altitude lies above any significant amount of stratospheric aerosol and is below altitudes where light scattered from the instrument primary mirror becomes significant.

\subsection{State vector specification}

Since the particle extinction and phase function are equally important to cloud property retrievals from limb-viewing measurements, and since both of these depend on the ice crystal effective size, retrievals are quite sensitive to the assumed particle size. Some sensitivity is removed by using the cloud extinction profile, $k(h)$, as the state parameter. Although the phase function still depends on the size distribution, the cloud particle phase functions from the database of Baum et al. (2005) vary smoothly with effective size and scattering angle in the OSIRIS solar scattering range, between 60 and $120^{\circ}$. Retrievals are performed with the state vector defined as the cloud extinction profile, $x_{i}=k_{\text {cloud }}\left(h_{i}\right)$, at heights corresponding to the tangent altitudes within the 
troposphere. Retrieval sensitivity to the assumed particle size is investigated in Sect. 6.2.

\subsection{Cloud scattering radiance signature}

The sensitivity of the measurement vector to small perturbations to the cloud extinction profile is illustrated in Fig. 12. In this figure the Jacobian matrix, $\mathbf{K}$, is shown for selected OSIRIS wavelengths that illustrate the change in sensitivity over the spectral range that was seen in Fig. 2. To produce these elements, cirrus cloud properties with effective size $D_{\mathrm{e}}=50 \mu \mathrm{m}$ were distributed at heights between 9 and $19 \mathrm{~km}$ at extremely low number densities such that the cloud optical thickness was $\tau_{\mathrm{c}}=0.03$. Elements of $\mathbf{K}$ were computed by perturbing the state vector elements at altitudes corresponding to the measurement tangent heights by $2 \%$ and taking a forward-difference derivative of the two measurement vectors. We see that the measurement vector shows good sensitivity to the specified state vector and that the variation with wavelength of $\mathbf{K}$ is consistent with the measured in-cloud and clear-sky spectra in Fig. 11. It is clear from the sensitivities shown in Fig. 12 that the use of the $750 \mathrm{~nm}$ radiance profile shows good sensitivity to the presence of cloud particles.

Due to the sensitivity of simulated limb radiances to the assumed surface albedo, the retrieved cloud extinction is also closely coupled to this value. As a result, the surface albedo is retrieved concurrently to the ice cloud extinction profile.

\subsection{Scene albedo retrieval}

The effective scene albedo is estimated from an OSIRIS scan by modeling the $675 \mathrm{~nm}$ radiance at a cloud- and aerosolfree reference altitude of $40 \mathrm{~km}$ for several values of surface albedo that span the range $a=[0,1]$. If the measured radiance falls within the range modeled radiances, the albedo is found by linear interpolation. Since the polarization sensitivity of the OS absolute calibration is extremely small near $675 \mathrm{~nm}$, and since this wavelength is sufficiently far from the center of the Chappuis $\mathrm{O}_{3}$ absorption band, radiances at this wavelength give a highly sensitive measure of surface albedo from high-altitude exposures. Once the albedo at $675 \mathrm{~nm}$ is calculated, this reference value is used to scale the wavelength-dependent albedo across the spectrum. The effective scene albedo computed in this fashion is distributed in the current OSIRIS data products (Degenstein et al., 2009; Bourassa et al., 2007, 2011, 2012).

\subsection{Cloud extinction retrievals from OSIRIS scans}

Since the radiance from OSIRIS at wavelengths near $750 \mathrm{~nm}$ is coupled to the surface albedo, the stratospheric aerosol amount, and to any cloud scattering properties, an iterative solution that adjusts each of these parameters to changes in the others is required to retrieve these properties.

The retrieval process proceeds as follows. First, the surface albedo is estimated using the technique just described when

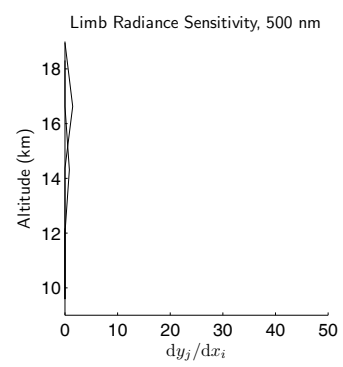

(a) $500 \mathrm{~nm}$

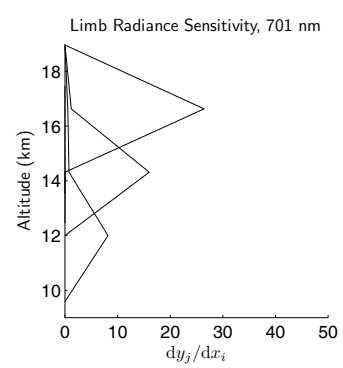

(c) $701 \mathrm{~nm}$

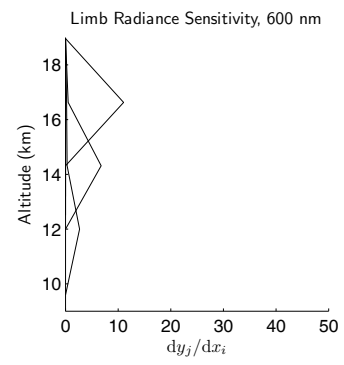

(b) $600 \mathrm{~nm}$

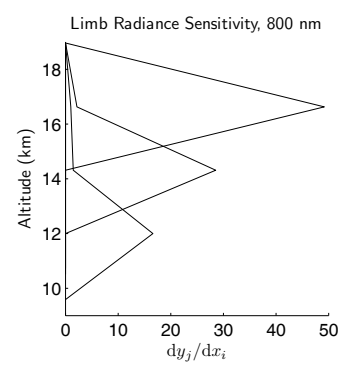

(d) $800 \mathrm{~nm}$
Fig. 12. Kernel matrix for selected wavelengths for scattering by $50 \mu \mathrm{m}$ particles.

only the a priori estimates of cloud and aerosol extinction are in place. Next, the stratospheric aerosol extinction profile is retrieved. Following this, the cloud extinction profile is retrieved, and further the surface albedo is again retrieved, with the model having fixed the cloud and aerosol extinction profiles to their retrieved values. The a priori estimate for the cloud particles is a cloud uniformly distributed between $10 \mathrm{~km}$ and the local tropopause with assumed optical thickness $\tau_{\mathrm{c}}=0.1$. The a priori aerosol number density for a non-volcanic stratospheric loading from Loughman et al. (2004) is used in this retrieval, which has a number density maximum near $0.5 \mathrm{~cm}^{-3}$ at $20 \mathrm{~km}$.

To retrieve the tropospheric cirrus cloud extinction profile, we retrieve sulphate aerosol extinction only within the stratosphere. As a demarcation between the two regions we use the potential temperature tropopause, $\Theta_{380 \mathrm{~K}}$, as a division between the characteristics of stratospheric and tropospheric air in the tropics (Holton et al., 1995). This division is used strictly in the tropics - defined for our purposes as any latitude less than $25^{\circ}$ - and the thermal lapserate tropopause is used elsewhere. Retrievals of stratospheric sulphate aerosol extinction assume particles distributed lognormally with mode radius $0.08 \mu \mathrm{m}$ and mode width 1.6 (Deshler et al., 2003). Below the $\Theta_{380 \mathrm{~K}}$ altitude, the aerosol number density is held fixed to a representative value of $1 \mathrm{~cm}^{-3}$, and is tapered slightly at lower altitudes to indicate a transition between the Junge layer and boundary-layer aerosols. The much higher concentrations of lower-altitude aerosols are accounted for by the scene albedo retrieval described in Sect. 5.4. With the aerosol profile thus fixed in the 
tropopause, cirrus cloud scattering properties for a specified effective size, $D_{\mathrm{e}}$, are assumed and retrievals of cloud extinction are performed. Since the retrieved state is essentially independent of its a priori estimate, the extinction profile is initialized to be a cloud distributed from $10 \mathrm{~km}$ up to $\Theta_{380 \mathrm{~K}}$ with total optical thickness $\tau=0.03$.

The profiles of retrieved extinctions and measurement vectors, for both the lower stratosphere (sulphate aerosols) and UTLS (cirrus cloud), for a measurement through a very thin cloud are shown in Fig. 13. In the extinction profiles shown in Fig. 13a and c, the light blue lines indicate successive iterations toward the retrieved profile. The a priori estimate in Fig. 13a is too small to be seen on this scale. In Fig. 13b and $\mathrm{d}$ the final modeled vectors, $\boldsymbol{F}\left(\boldsymbol{x}^{(n)}, \tilde{b}\right)$, shown as heavy blue lines, match the measured vectors very well. For the cloud measurement vector there is a small overestimation of $\boldsymbol{y}$ at $14.5 \mathrm{~km}$, for which the cloud extinction is not sufficiently low, which is typical for measurements at tangent altitudes below a strongly-scattering region. The extinction profile gives a layer approximately $2 \mathrm{~km}$ thick, which when integrated yields a cloud optical thickness of $\tau_{\mathrm{c}}=0.0075$, which corresponds to a subvisual cirrus cloud according to the standard criteria $\tau_{\mathrm{svc}} \leq 0.03$ (Sassen and Cho, 1992).

With no cloud properties in the model, the increased upwelling radiation that is actually due to the presence of a cloud is attributed to an increased surface albedo of $a=0.288$. With the sparsely-distributed a priori cloud profile, the retrieved value is $a=0.292$, but in the presence of the retrieved cloud layer the retrieved albedo is decreased to $a=0.278$.

\subsection{Retrieval performance}

In the MART retrieval of the cloud extinction profile we find that fifteen iterations of the relaxation step, Eq. (3), are sufficient to obtain convergence and to obtain a reasonable estimate of the cloud extinction profile. In total, the processing chain with six aerosol iterations and fifteen cloudparticle iterations currently takes approximately $30 \mathrm{~min}$ for one OSIRIS scan on a desktop computer with a $2.5 \mathrm{GHz}$ processor and $16 \mathrm{~GB}$ of RAM.

\section{Sensitivity analysis}

We briefly investigate the sensitivity of the retrieved cirrus cloud extinction profile to several auxiliary model parameters. For these sensitivity studies, we consider the variation to the cloud extinction profile retrieved in Sect. 5.5. Since both the surface albedo and the assumed effective particle size can modify the limb radiance in a way similar to the cloud properties, we study their effects on cloud extinction retrieval accuracy.
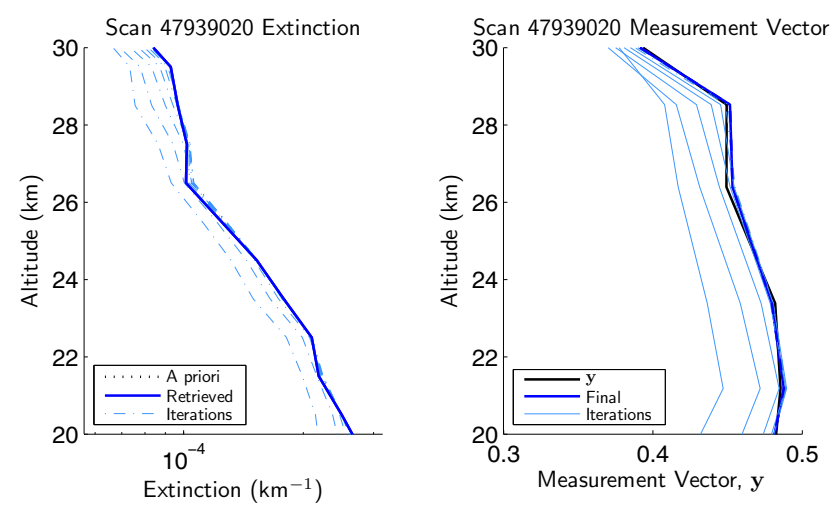

(a) Aerosol extinction

(b) Aerosol measurement vector
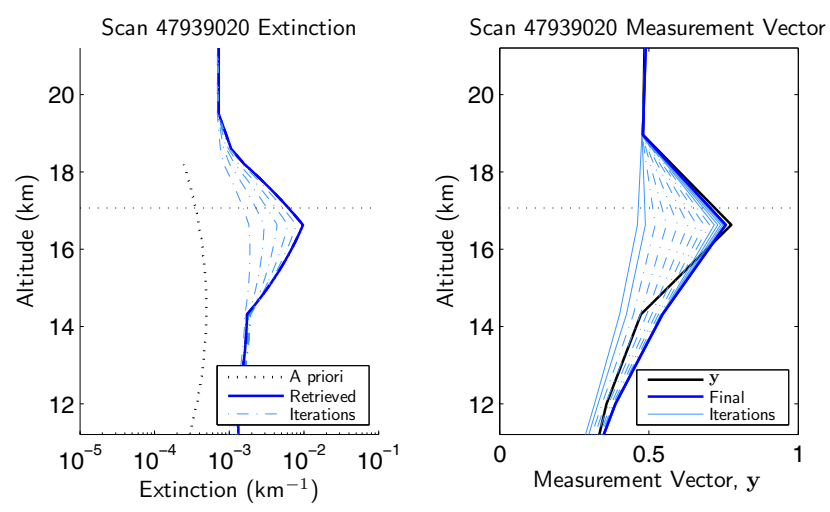

(c) Cloud extinction

(d) Cloud measurement vector

Fig. 13. Stratospheric and UTLS profiles of retrieved extinction and measurement vectors for OSIRIS scan 47939020.

\subsection{Sensitivity to surface albedo}

For this sensitivity study, we consider a wavelengthindependent albedo, which is quite reasonable since the parameterized albedos used in this work vary slowly with wavelength between 470 and $750 \mathrm{~nm}$. As a base case, the extinction profile is retrieved using the average planetary albedo of $a=0.3$, then set alternately to $a=0.2$ and to $a=0.4$ for separate retrievals. The retrieved extinction profiles and percent differences in the retrieved extinction are shown in Fig. 14a. For a smaller value of surface albedo, the extinction profile throughout the cloud region is higher by a factor of approximately $15 \%$, as shown in Fig. 14b. In this case, because the assumed surface albedo is lower, the additional radiance is attributed to a slightly increased amount of cloud scattering. When a larger value of surface albedo is used, the opposite occurs, and the retrieved extinction is lower by a factor of approximately $10 \%$. The retrieved cloud optical thicknesses are $\tau_{\mathrm{c}}=0.0084(a=0.2), 0.0075(a=0.3)$, and 0.0067 $(a=0.4)$.

The retrieved cloud optical thickness changes here by at most $25 \%$, depending on the accuracy of the surface albedo, 

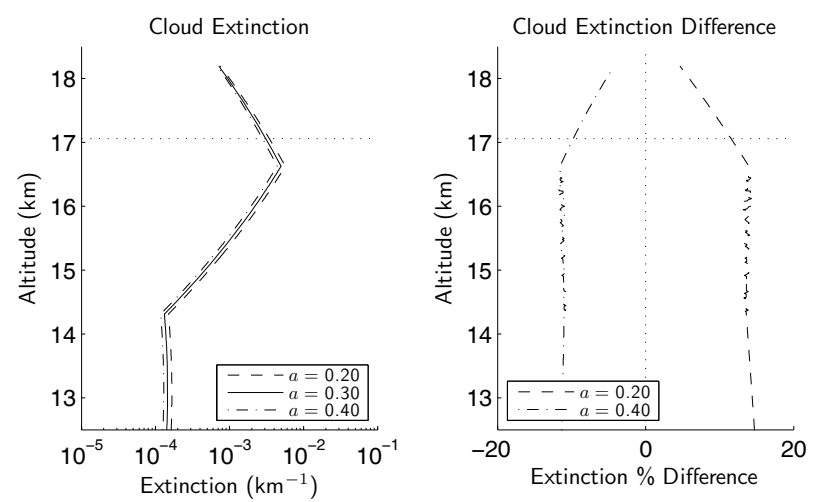

(a) Retrieved cirrus extinctions (b) Difference in retrieved extinctions

Fig. 14. Retrieved cirrus extinction for varying surface albedo, scan 47939020.

which in this case was $50 \%$. The sensitivity of the scene albedo to aerosol loading, retrieved in this way, has been found to be at most $20 \%$ (Bourassa et al., 2012). Since the coupling of the retrieved albedo to cirrus cloud loading is similar to its relation to aerosols, it is reasonable to assume that the variability shown in this section forms an upper bound on the sensitivity of the optical thickness to the scene albedo.

\subsection{Sensitivity to cloud effective particle size}

Since these retrievals of the cloud extinction profile first assume an effective particle size, the sensitivity to the particle size is also studied. We retrieve the extinction profile from the same OSIRIS scan, but for assumed effective particle sizes of 40 and $60 \mu \mathrm{m}$. This range of effective sizes has been chosen primarily to study retrievals when scattering is dominated by hexagonal plates and columns. This range of effective sizes lies on the large side of the range given by Lawson et al. (2008), $R_{\text {eff }} \approx 10 \mu \mathrm{m}$, and by Heymsfield (1986), $R_{\text {eff }} \leq 50 \mu \mathrm{m}$.

The percent differences in the retrieved extinction profile, when compared to the retrieved profile obtained when using the $D_{\mathrm{e}}=50 \mu \mathrm{m}$ is used, are shown in Fig. 15. When a smaller effective particle size is assumed, the scattering cross section is smaller, and a larger number of cloud particles are used within the model to obtain the same modeled radiance. In this case, the retrieved extinction profile is higher by a factor of up to $10 \%$. When a larger particle size is assumed, the larger scattering cross section results in a smaller retrieved cloud particle number density such that the extinction profile is smaller by at most $5 \%$. The retrieved optical thicknesses are $\tau_{\mathrm{c}}=0.0080\left(D_{\mathrm{e}}=40 \mu \mathrm{m}\right), 0.0075\left(D_{\mathrm{e}}=50 \mu \mathrm{m}\right)$, and 0.0071 $\left(D_{\mathrm{e}}=60 \mu \mathrm{m}\right)$.

Since the extinction retrieval is closely coupled to the assumed effective size, comparisons between the measured and
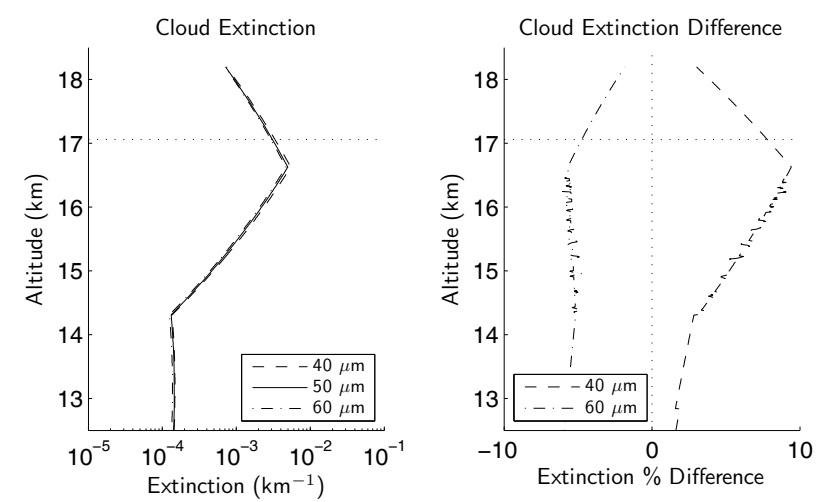

(a) Retrieved cirrus extinctions

(b) Difference in retrieved extinctions

Fig. 15. Retrieved cirrus extinction for varying assumed particle size, scan 47626029.

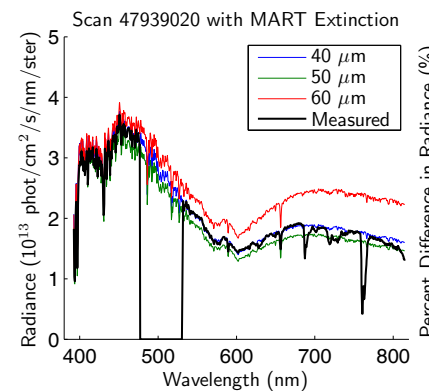

(a) Spectral radiances

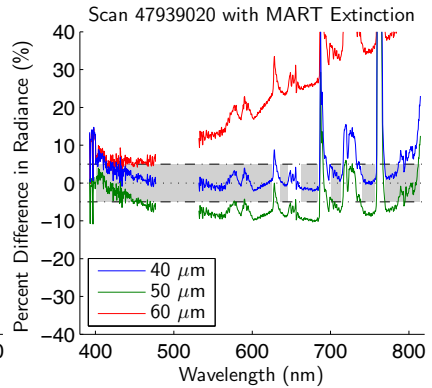

(b) Radiance percent difference
Fig. 16. In-cloud radiances modeled with retrieved extinction profile for several assumed particle sizes.

modeled spectra are done to obtain an estimate of the bestfit effective size. The spectra modeled with the retrieved extinction profiles for each of the three assumed particle sizes are shown in Fig. 16, together with the percent difference in modeled radiance with respect to the measured spectrum. In this figure, the retrieved extinction profile with $D_{\mathrm{e}}=40 \mu \mathrm{m}$ gives an excellent match across the spectrum with percent difference in radiance of less than $3 \%$. The retrieved extinction with $D_{\mathrm{e}}=60 \mu \mathrm{m}$ over-estimates the radiance for this measurement, and the radiances for $D_{\mathrm{e}}=50 \mu \mathrm{m}$ slightly under-estimate the in-cloud radiance.

For each of these effective sizes the computed vector, $\boldsymbol{F}\left(\boldsymbol{x}^{(n)}, \tilde{b}\right)$, agrees very well with the measured vector, $\boldsymbol{y}$, throughout the region of interest, as shown in Fig. 17, where the final computed vectors for each effective size is shown together with $\boldsymbol{y}$. The simulated measurement vectors for the three effective sizes all overlie each other, but the extinction profiles that generate them produce significantly different agreement with the measured in-cloud spectrum, as illustrated in Fig. 16. Due to the differing scattering behaviours of 

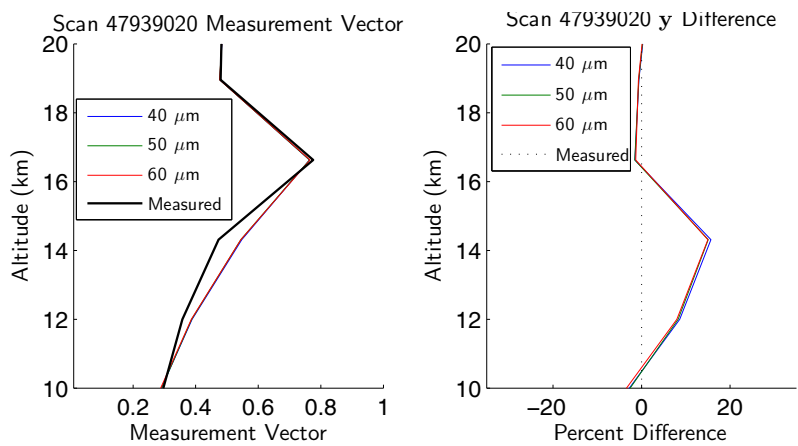

(a) Measurement vectors

(b) Modeled vector differences

Fig. 17. Measurement vectors for OSIRIS scan 47626029. Final modeled measurement vector, $\boldsymbol{F}\left(\boldsymbol{x}^{(n)}, \tilde{b}\right)$, for the three assumed effective particle sizes are shown with the true measured vector, $\boldsymbol{y}$, together with their percent differences with $y$.

the three particle sizes, only the $D_{\mathrm{e}}=40 \mu \mathrm{m}$ extinction profile is able to model accurately the measured spectrum.

\subsection{Sensitivity: summary}

From the results shown in Figs. 16 and 17, it is clear that re-modeling the measured radiances at selected wavelengths across the spectrum is a key element in the characterization of detected clouds by both an optical thickness and an effective size. While the present study has focused on retrieving cloud optical thickness for an assumed value of $D_{\mathrm{e}}$, retrievals of effective particle size must include spectral fitting at wavelengths above $700 \mathrm{~nm}$ using the various retrieved extinction profiles to supply information about the measured value of $D_{\text {e. }}$.

Although the retrieved cloud properties presented in these sections have been performed for only a few OSIRIS scans, they demonstrate clearly that it is possible to make a firm inference of SVC cloud optical thickness and to estimate the effective particle size from OSIRIS measurements of limbscattered spectral radiance.

\section{Conclusions}

In this work we have demonstrated the ability to retrieve the optical properties of subvisual cirrus clouds from OSIRIS limb scattering measurements. This was achieved in two steps. First, it was shown that with several specific configurations, the SASKTRAN model accurately simulates the incloud spectral radiances measured from a limb-scattering geometry. Next, by using this model in a retrieval algorithm that assumes an effective cloud particle size, an extinction profile was retrieved that replicates the measured spectrum to high accuracy.
The model computations in this work were performed with a radiative transfer model that uses a ray-tracing, successiveorders of scatter algorithm in a fully spherical geometry. With the configuration described in this work, this model can compute limb radiances from thin and subvisual cirrus clouds with optical thicknesses up to $\tau_{\mathrm{c}}=0.7$ for effective particle sizes between 10 and $180 \mu \mathrm{m}$. The retrieval algorithm described in this work estimates simultaneously from an OSIRIS limb scan the surface albedo together with extinction profiles for both stratospheric sulphate aerosol and cirrus clouds.

The technique presented in this paper has demonstrated the ability to retrieve the optical thickness of SVC, for an assumed effective cloud particle size, using the limb-scattered radiance profiles at two wavelengths. While it was been shown that this optical thickness is most sensitive to the a priori effective cloud particle size, it has also been shown that a spectral fitting technique using the retrieved optical thickness has potential to be used in a more complete optical property retrieval.

The benefits of obtaining a long-term record of SVC optical properties both for quantifying trace gas retrieval uncertainties and for improved SVC representations within large-scale models are clear. The results shown in this work demonstrate a first step towards obtaining an eleven-year record of global SVC optical properties.

Acknowledgements. This work was supported by the Canadian Space Agency, the Natural Sciences and Engineering Research Council (Canada) and the European Space Agency. Odin is a Swedish-led satellite project funded jointly by Sweden (SNSB), Canada (CSA), France (CNES) and Finland (Tekes).

Edited by: C. von Savigny

\section{References}

Baum, B., Heymsfield, A., Yang, P., and Bedka, S.: Bulk scattering properties for the remote sensing of ice clouds, Part I: Microphysical data and models, J. Appl. Meteorol., 44, 1885-1895, doi:10.1175/JAM2308.1, 2005.

Bourassa, A., Degenstein, D., and Llewellyn, E.: Climatology of the subvisual cirrus clouds as seen by OSIRIS on Odin, Adv. Space Res., 36, 807-812, doi:10.1016/j.asr.2005.05.045, 2005.

Bourassa, A., Degenstein, D., Gattinger, R., and Llewellyn, E.: Stratospheric aerosol retrieval with Optical Spectrograph and InfraRed Imaging System limb scatter measurements, J. Geophys. Res, 112, D10217, doi:10.1029/2006JD008079, 2007.

Bourassa, A., Degenstein, D., and Llewellyn, E.: SASKTRAN: A spherical geometry radiative transfer code for efficient estimation of limb scattered sunlight, J. Quant. Spectrosc. Ra., 109, 52-73, doi:10.1016/j.jqsrt.2007.07.007, 2008.

Bourassa, A. E., McLinden, C. A., Sioris, C. E., Brohede, S., Bathgate, A. F., Llewellyn, E. J., and Degenstein, D. A.: Fast $\mathrm{NO}_{2}$ retrievals from Odin-OSIRIS limb scatter measurements, Atmos. Meas. Tech., 4, 965-972, doi:10.5194/amt-4-965-2011, 2011. 
Bourassa, A. E., Rieger, L. A., Lloyd, N. D., and Degenstein, D. A.: Odin-OSIRIS stratospheric aerosol data product and SAGE III intercomparison, Atmos. Chem. Phys., 12, 605-614, doi:10.5194/acp-12-605-2012, 2012.

Chahine, M.: A general relaxation method for inverse solution of the full radiative transfer equation, J. Atmos. Sci., 29, 741-747, doi:10.1175/1520-0469(1972)029<0741:AGRMFI>2.0.CO;2, 1972.

Degenstein, D. A., Bourassa, A. E., Roth, C. Z., and Llewellyn, E. J.: Limb scatter ozone retrieval from 10 to $60 \mathrm{~km}$ using a multiplicative algebraic reconstruction technique, Atmos. Chem. Phys., 9, 6521-6529, doi:10.5194/acp-9-6521-2009, 2009.

Deshler, T., Hervig, M., Hofmann, D., Rosen, J., and Liley, J.: Thirty years of in situ stratospheric aerosol size distribution measurements from Laramie, Wyoming $(41 \mathrm{~N})$, using balloon-borne instruments, J. Geophys. Res., 108, 4167, doi:10.1029/2002JD002514, 2003.

Feister, U. and Grewe, R.: Spectral albedo measurements in the UV and visible region over different types of surfaces, Photochem. Photobiol., 62, 736-744, 1995.

$\mathrm{Fu}, \mathrm{Q}$., Hu, Y., and Yang, Q.: Identifying the top of the tropical tropopause layer from vertical mass flux analysis and CALIPSO lidar cloud observations, Geophys. Res. Lett., 34, L14813, doi:10.1029/2007GL030099, 2007.

Fueglistaler, S., Dessler, A., Dunkerton, T., Folkins, I., Fu, Q., and Mote, P.: Tropical Tropopause Layer, Rev. Geophys., 47, RG1004, doi:10.1029/2008RG000267, 2009.

Herman, B., Ben-David, A., and Thome, K.: Numerical technique for solving the radiative transfer equation for a spherical shell atmosphere, Appl. Optics, 33, 1760-1770, doi:10.1364/AO.33.001760, 1994.

Heymsfield, A.: Ice Particles Observed in a Cirriform Cloud at $-83^{\circ} \mathrm{C}$ and Implications for Polar Strotospheric Clouds, J. Atmos. Sci., 43, 851-855, doi:10.1175/15200469(1986)043<0851:IPOIAC > 2.0.CO;2, 1986.

Heymsfield, A., Bansemer, A., Field, P., Durden, S., Stith, J., Dye, J., Hall, W., and Grainger, C.: Observations and parameterizations of particle size distributions in deep tropical cirrus and stratiform precipitating clouds: Results from in situ observations in TRMM field campaigns, J. Atmos. Sci., 59, 3457-3491, doi:10.1175/1520-0469(2002)059<3457:OAPOPS > 2.0.CO;2, 2002.

Holton, J., Haynes, P., McIntyre, M., Douglass, A., Rood, R., and Pfister, L.: Stratosphere-troposphere exchange, Rev. Geophys., 33, 403-439, doi:10.1029/95RG02097, 1995.

Jensen, E. J., Pfister, L., Bui, T. V., Lawson, P., Baker, B., Mo, Q., Baumgardner, D., Weinstock, E. M., Smith, J. B., Moyer, E. J., Hanisco, T. F., Sayres, D. S., Clair, J. M. St., Alexander, M. J., Toon, O. B., and Smith, J. A.: Formation of large $(\sim 100 \mu \mathrm{m})$ ice crystals near the tropical tropopause, Atmos. Chem. Phys., 8, 1621-1633, doi:10.5194/acp-8-1621-2008, 2008.

Jin, Z., Charlock, T., Smith Jr., W., and Rutledge, K.: A parameterization of ocean surface albedo, Geophys. Res. Lett., 31, L22301, doi:10.1029/2004GL021180, 2004.

Kistler, R., Kalnay, E., Collins, W., Saha, S., White, G., Woollen, J., Chelliah, M., Ebisuzaki, W., Kanamitsu, M., Kousky, V., Kousky, V., van den Dool, H., Jenne, R., and Fiorino, M.: The NCEPNCAR 50-Year Reanalysis: Monthly Means CD-ROM and Documentation, B. Am. Meteorol. Soc., 82, 247-267, 2001.
Lawson, R. P., Pilson, B., Baker, B., Mo, Q., Jensen, E., Pfister, L., and Bui, P.: Aircraft measurements of microphysical properties of subvisible cirrus in the tropical tropopause layer, Atmos. Chem. Phys., 8, 1609-1620, doi:10.5194/acp-8-1609-2008, 2008.

Llewellyn, E., Lloyd, N., Degenstein, D., Gattinger, R., Petelina, S., Bourassa, A., Wiensz, J., Ivanov, E., McDade, I., Solheim, B., McConnell, J. C., Haley, C. S., von Savigny, C., Sioris, C. E., McLinden, C. A., Griffioen, E., Kaminski, J., Evans, W. F., Puckrin, E., Strong, K., Wehrle, V., Hum, R. H., Kendall, D. J., Matsushita, J., Murtagh, D. P., Brohede, S., Stegman, J., Witt, G., Barnes, G., Payne, W. F., Piché, L., Smith, K., Warshaw, G., Deslauniers, D. L., Marchand, P., Richardson, E. H., King, R. A., Wevers, I., McCreath, W., Kyrölä, E., Oikarinen, L., Leppelmeier, G. W., Auvinen, H., Mégie, G., Hauchecorne, A., Lefèvre, F., de La Nöe, J., Ricaud, P., Frisk, U., Sjoberg, F., von Schéele, F., and Nordh, L.: The OSIRIS instrument on the Odin spacecraft, Can. J. Phys., 82, 411-422, doi:10.1139/p04005, 2004.

Loughman, R., Griffioen, E., Oikarinen, L., Postylyakov, O., Rozanov, A., Flittner, D., and Rault, D.: Comparison of radiative transfer models for limb-viewing scattered sunlight measurements, J. Geophys. Res., 109, D06303, doi:10.1029/2003JD003854, 2004.

Lynch, D., Sassen, K., Starr, D., and Stephens, G.: Cirrus, Oxford University Press, USA, 2002.

Martins, E., Noel, V., and Chepfer, H.: Properties of cirrus and subvisible cirrus from nighttime Cloud-Aerosol Lidar with Orthogonal Polarization (CALIOP), related to atmospheric dynamics and water vapor, J. Geophys. Res., 116, D02208, doi:10.1029/2010JD014519, 2011.

McKellar, B. and Box, M.: The scaling group of the radiative transfer equation, J. Atmos. Sci., 38, 1063-1068, doi:10.1175/15200469(1981)038<1063:TSGOTR > 2.0.CO;2, 1981.

McLinden, C., McConnell, J., Griffioen, E., and McElroy, C.: A vector radiative-transfer model for the Odin/OSIRIS project, Can. J. Phys., 80, 375-393, doi:10.1139/p01-156, 2002.

Mergenthaler, J., Roche, A., Kumer, J., and Ely, G.: Cryogenic limb array etalon spectrometer observations of tropical cirrus, J. Geophys. Res., 104, 22183-22194, doi:10.1029/1999JD900397, 1999.

Sassen, K. and Cho, B.: Subvisual-Thin Sirrus Lidar Dataset for Satellite Verification and Climatological Research, J. Appl. Meteorol., 31, 1275-1285, doi:10.1175/15200450(1992)031<1275:STCLDF>2.0.CO;2, 1992.

Sloan, I. and Womersley, R.: Extremal systems of points and numerical integration on the sphere, Adv. Comp. Math., 21, 107-125, doi:10.1023/B:ACOM.0000016428.25905.da, 2004.

Spang, R., Eidmann, G., Riese, M., Offermann, D., Preusse, P., Pfister, L., and Wang, P.: CRISTA observations of cirrus clouds around the tropopause, J. Geophys. Res., 107, 8174, doi:10.1029/2001JD000698, 2002.

Spang, R., Arndt, K., Dudhia, A., Höpfner, M., Hoffmann, L., Hurley, J., Grainger, R. G., Griessbach, S., Poulsen, C., Remedios, J. J., Riese, M., Sembhi, H., Siddans, R., Waterfall, A., and Zehner, C.: Fast cloud parameter retrievals of MIPAS/Envisat, Atmos. Chem. Phys., 12, 7135-7164, doi:10.5194/acp-12-71352012, 2012. 
Tian, L., Heymsfield, G., Li, L., Heymsfield, A., Bansemer, A., Twohy, C., and Srivastava, R.: A study of cirrus ice particle size distribution using TC4 observations, J. Atmos. Sci., 67, 195-216, 2010.

Wang, P., Minnis, P., McCormick, M., Kent, G., and Skeens, K.: A 6-year climatology of cloud occurrence frequency from Stratospheric Aerosol and Gas Experiment II observations (1985-1990), J. Geophys. Res., 101, 29407-29429, doi:10.1029/96JD01780, 1996.
Wiensz, J., Bourassa, A., Lloyd, N., Wiacek, A., Martin, R., and Degenstein, D.: Photon Conservation in Scattering by Large Ice Crystals with the SASKTRAN Radiative Transfer Model, J. Quant. Spectrosc. Ra., 113, 582-593, doi:10.1016/j.jqsrt.2012.02.007, 2012. 